\title{
Saúde indígena: contribuição da Seção de Hepatologia do Instituto Evandro Chagas desde a década de 1980
}

\section{Indigenous health: contribution of the Hepatology Section from Instituto Evandro Chagas since the 1980 s}

Heloisa Marceliano Nunes, Manoel do Carmo Pereira Soares

Instituto Evandro Chagas/SVS/MS, Seção de Hepatologia, Belém, Pará, Brasil

\begin{abstract}
RESUMO
Os primeiros trabalhos desenvolvidos no Instituto Evandro Chagas (IEC) envolvendo populações indígenas datam do final da década de 1980, quando foram diagnosticados, sorologicamente, casos de hepatite B e D em indígenas da etnia Munduruku. A partir desse evento, várias pesquisas foram realizadas envolvendo as hepatites virais entre grupos indígenas na Amazônia brasileira, assim como um estudo sobre capilaríase hepática em grupos indígenas do Estado de Mato Grosso. O objetivo deste trabalho foi apresentar as pesquisas realizadas na Seção de Hepatologia do IEC desde a década de 1980 até a presente data. $\bigcirc$ artigo foi desenvolvido baseando-se em publicações existentes no acervo do IEC e em trabalhos publicados em revistas especializadas. Foram selecionados 11 estudos que envolveram as etnias indígenas Munduruku, Yanomami, Kanamary, Jamamadi, Parakanã, Nambikwara, Kithãulu, Negarotê e Xikrin, os quais revelaram o status da saúde desses indígenas. Essas pesquisas demonstraram o comprometimento da saúde dos índios de diferentes etnias na Amazônia, contribuindo para o conhecimento das doenças hepáticas nessas populações para controle e acompanhamento.
\end{abstract}

Palavras-chave: Hepatites Virais; Capilaríase Hepática; Soroprevalência; Indígenas.

\begin{abstract}
The first studies carried out in the Instituto Evandro Chagas (IEC) involving indigenous populations are dated from the late 1980s, when cases of hepatitis B and D in the Munduruku indigenous ethnicity were diagnosed serologically. From that event, several studies were conducted involving viral hepatitis among indigenous groups in the Brazilian Amazon, as well as a study of hepatic capillariasis in indigenous groups of Mato Grosso State. The aim of this study was to present the researches at the Hepatology Section of the IEC, from the 1980s to nowadays. This study was developed based on publications from the scientific collection of IEC and in papers published in journals. Eleven studies that involved the indigenous ethnic groups Munduruku Yanomami Kanamary, Jamamadi, Parakanã, Nambikwara, Kithãulu, Negarotê and Xikrin were selected, which revealed their health condition. These researches showed health problems of Indians from different ethnic groups in the Amazon, contributing to the knowledge of liver diseases in these populations in order to control and monitor them.
\end{abstract}

Keywords: Hepatitis, Viral; Hepatic Capillariasis; Seroprevalence; Indigenous.

\footnotetext{
Correspondência / Correspondence:

Heloisa Marceliano Nunes

Instituto Evandro Chagas/SVS/MS, Seção de Hepatologia

Av. Almirante Barroso, 492. Bairro: Marco - CEP: 66093-020 - Belém, Pará, Brasil - Tel.: +55 (91) 3214-2131

E-mail: heloisanunes@iec.pa.gov.br
} 


\section{INTRODUÇÃO}

Datam de 1951 os primeiros deslocamentos de uma equipe do Instituto Evandro Chagas (IEC) ao Município de Lábrea, Estado do Amazonas, Brasil, para coletar material de pacientes com febre e icterícia. Em maio de 1964, os drs. Robert E. Shope e Gilberta Bensabath iniciaram, naquele Município, atividades sistematizadas do IEC para esclarecer a etiologia de hepatopatias da Amazônia Ocidental, motivadas pela ocorrência de cinco óbitos de crianças'. Os estudos epidemiológicos sobre as hepatites virais no Instituto prosseguiram, em 1965, devido à presença de uma hepatoencefalopatia que foi denominada de "hepatite de Lábrea", mesmo nome do Município de ocorrência ${ }^{1,2,3}$.

Referente às hepatites em populações indígenas, os primeiros estudos sistemáticos realizados pelo IEC datam de 1989, quando foram diagnosticados sorologicamente casos de hepatite B e Delta (D) em indígenas da etnia Munduruku, no Município de Itaituba, sudoeste do Estado do Pará, Brasil, e transcorreram até 2004, com um estudo acerca da soroprevalência dos vírus das hepatites $B$ (VHB) e D (VHD) nas aldeias Apyterewa e Xingu, da etnia Parakanã, no Município de Altamira, Estado do Pará.

O presente artigo histórico visa apresentar os diversos estudos realizados com as etnias indígenas Munduruku, Yanomami, Kanamary, Jamamadi, Parakanã, Nambikwara, Kithãulu, Negarotê e Xikrin pela Seção de Hepatologia (SAHEP) do IEC, órgão atualmente subordinado à Secretaria de Vigilância em Saúde do Ministério da Saúde (MS). Para isso, foram analisadas as pesquisas realizadas em populações indígenas pela SAHEP/IEC, anteriormente denominada Laboratório de Hepatopatias, constantes de seu acervo, incluindo o Relatório dos 50 Anos do Instituto Evandro Chagas (1936-1986), o Relatório Qüinqüenal (1991-1995), O Relatório Trianual (1996-1998) e artigos publicados em revistas especializadas. Foram selecionados 11 trabalhos, descritos de forma resumida, apresentados e discutidos a seguir.

\section{TRIBOS INDÍGENAS DA AMAZÔNIA ORIENTAL COMO POPULAÇÃO DE RISCO PARA A HEPATITE D ${ }^{4}$}

A partir de 1989, o Laboratório de Hepatopatias do IEC diagnosticou sorologicamente quatro casos de hepatite $D$ em indígenas da etnia Munduruku do Município de Itaituba. Todos os casos examinados eram de portadores crônicos de hepatite $D$, e dois casos evoluíram para óbito. Como consequência, em setembro de 1990, o IEC, apoiado pela Fundação Nacional do Índio, procedeu à investigação soroepidemiológica na área, coletando 436 amostras de soro de indígenas da etnia Munduruku, cuja média de idade variou entre 1 e 70 anos, nas aldeias Sai Cinza, Kaburuá e Katõ.

Foi detectada a prevalência de $66 \%$ de marcadores de infecção pregressa pelo $\mathrm{VHB}$ e, em $50 \%$ dos portadores do antígeno de superfície do VHB (HBsAg), havia também positividade para o anticorpo do VHD (anti-HD).
Naquela época, O IEC já havia registrado casos de hepatite $D$ em garimpeiros procedentes de Itaituba, conhecido por suas inúmeras áreas garimpeiras, considerando-se a hipótese de que a introdução do VHD poderia ter ocorrido pela relação existente entre indígenas e garimpeiros daquela região.

Essas observações expuseram, para reflexão, alguns aspectos preocupantes que deveriam prioritariamente ser analisados pelos pesquisadores envolvidos no assunto, como: a) a existência de tribos indígenas com elevada prevalência de portadores do $\mathrm{HBsAg}$, a frequente relação dessas tribos com áreas de garimpo e o potencial migratório dos garimpeiros entre os vários garimpos da Amazônia, isso tudo podendo levar à disseminação da infecção com repercussões de gravidade variável; b) o estilo de vida dos indígenas os colocava como "grupos de risco" para as infecções pelo VHB e VHD na Amazônia, sendo, pois, justificado um possível programa de imunização; e c) já se ter documentado epidemia de hepatite $D$ com elevada letalidade em tribo indígena do norte da América do Sul, com alta prevalência de portadores do HBsAg. Essa tribo era de indígenas da etnia Yucpa, da Venezuela, onde 149 indígenas desenvolveram hepatite, entre esses, 34 foram a óbito e 22 evoluíram para hepatite crônica B. O HBsAg foi encontrado em $65 \%$ daqueles indígenas, entre eles, $80 \%$ eram anti-HD positivo, e o antígeno $D$ foi detectado na autópsia de sete pacientes $^{5}$.

\section{SOROEPIDEMIOLOGIA DAS HEPATITES EM COMUNIDADES INDÍGENAS ${ }^{6}$}

O Relatório Quinquenal do IEC, referente aos anos de 1991 a 1995, apresentou um levantamento com o intuito de promover a análise e a discussão dos diversos aspectos epidemiológicos relacionados à transmissão dos vírus das hepatites nas comunidades indígenas da Amazônia brasileira; de iniciar uma série de considerações sobre o assunto, fundamentadas em critérios históricos, antropológicos, ecoepidemiológicos, clínicos e laboratoriais; e de desenhar uma política adequada de prevenção e controle para essas populações. Nesse período, foram desenvolvidas pesquisas entre indígenas das etnias Yanomami, Kanamary, Jamamadi, Munduruku e Parakanã.

\section{ETNIA YANOMAMI}

Entre os meses de novembro e dezembro de 1991, um inquérito soroepidemiológico foi realizado em indivíduos da área indígena Yanomami, Estado de Roraima, Brasil. Foram coletadas 289 amostras de soro de indígenas de várias comunidades Yanomami, com idade variando entre 6 meses e 80 anos, com média de $20,45 \pm 13,35$ anos.

A testagem das amostras, realizada por técnica imunoenzimática, detectou 7,3\% (21/289) portadores do HBsAg. Entre esses, foi encontrada a prevalência de $38 \%(8 / 21)$ anti-HD em sete indígenas da comunidade Alto Catrimani e um indígena da área Paapiú. 
O estudo identificou a presença de infecção pelo VHD e a ocorrência de óbito de um paciente sorologicamente comprovado como portador de superinfecção pelo VHD, com doença hepática crônica descompensada; 15 meses após o início do quadro agudo, foi registrada infecção pelo vírus da hepatite C (VHC) relacionada à hepatopatia crônica, que necessitaria de investigação adicional. Foi sugerido que a introdução do VHD seria recente nessa população, talvez relacionada à atividade garimpeira na região, tendo sido recomendado, entre outras medidas, intensificar a vacinação contra o VHB.

\section{ETNIA KANAMARY}

No período de 18 a 22 de junho de 1993, por solicitação do Grupo de Trabalho para o Controle das Hepatites Virais do Centro Nacional de Epidemiologia, da Fundação Nacional de Saúde (FNS) do MS, em decorrência de casos de hepatite fulminante que evoluíram para óbito na área indígena Kanamary, localizada no Município de Atalaia do Norte, Estado do Amazonas, foi requerido ao IEC que, junto com uma equipe do MS, formada pelo dr. Edwin Castillo e a enfermeira Denise Moraes, procedessem a coleta de amostras para realização de testes sorológicos dos marcadores das hepatites virais tanto de pacientes como da população investigada.

Foram coletadas 198 amostras de sangue de indivíduos assintomáticos e sete amostras de pacientes com sintomas e sinais de doença hepática das aldeias São Luís e Lameirão (Rio Javari), Massapê (Rio Itacoaí), Ituí (Rio Ituí), Lobo (Igarapé do Lobo) e Matsés (Rio Jaquirana).

Em relação ao $\mathrm{VHB}$, houve prevalência de $17,7 \%$ de portadores, $72,2 \%$ tinham história anterior de infecção, $66,7 \%$ tinham perfil vacinal e $85,7 \%$ apresentaram resultados compatíveis com hepatite B. Entre os $\mathrm{HBsAg}$ positivo, 31,4\% apresentaram positividade para o anti-HD.

\section{ETNIA JAMAMADI}

Nos dias 9 e 10 de setembro de 1993, foi realizado inquérito soroepidemiológico na área indígena Jamamadi, localizada no Igarapé Santo Antonio, Município de Boca do Acre, Estado do Amazonas, desencadeado por informações acerca de óbitos por hepatite fulminante ocorridos naquela área.

Foram coletadas 90 amostras de sangue, duas delas apresentaram $\mathrm{HBsAg}$ positivo, 45 eram anti-HBc positivo; houve positividade para $\circ$ anti-VHC em uma amostra e outra para anti-HD. Em resposta aos resultados encontrados, foi providenciada, pelo IEC, a vacinação contra o VHB dos indígenas suscetíveis.

\section{ETNIA MUNDURUKU}

Em expedição realizada para a área indígena Munduruku, em Itaituba, no período de 25 de novembro a 5 de dezembro de 1994, foram coletadas 444 amostras de soro de indígenas para inquérito soroepidemiológico dos marcadores de infecção das hepatites B, C e D (Tabela 1).

Nas localidades Lago do Boto e Bom Futuro, a equipe foi informada de que haviam ocorrido vários óbitos em crianças compatíveis com hepatite fulminante. Com base nas evidências apresentadas, observou-se que provavelmente a ocorrência dos óbitos estava relacionada à coinfecção VHB/VHD, explicando, assim, a baixa prevalência de portadores da hepatite $\mathrm{D}$ em algumas das comunidades estudadas. Durante a expedição, foram detectados 35 pacientes com sinais/sintomas de doença hepática crônica, entre eles um paciente foi positivo para $\circ \mathrm{HBsAg}, 16$ para $\circ$ anti-HBc e/ou anti-HBs e não houve positividade para o anti-VHC.

Tabela 1 - Sorologia viral em indígenas Munduruku assintomáticos, conforme o local de procedência, novembro de 1994

\begin{tabular}{|c|c|c|c|c|c|c|}
\hline \multirow{2}{*}{ Aldeia/Local } & \multirow{2}{*}{ Total examinado } & \multicolumn{5}{|c|}{ Sorologia (positiva) } \\
\hline & & $\mathrm{HBsAg}$ & Anti-HBc & Anti-HBs & Anti-HD & Anti-VHC \\
\hline Waro Apompo & 99 & 1 & 22 & 24 & - & - \\
\hline Morro do Kurap & 18 & - & 3 & 2 & - & 1 \\
\hline São Manoel & 11 & 2 & 8 & 6 & - & - \\
\hline Bom Futuro & 65 & 8 & 43 & 37 & 1 & 1 \\
\hline Lago do Boto & 22 & 1 & 19 & 15 & - & - \\
\hline Missão Cururu & 36 & - & 11 & 11 & - & - \\
\hline Teles Pires & 96 & 1 & 69 & 65 & - & 6 \\
\hline Restinga & 43 & - & 17 & 15 & - & 1 \\
\hline Santa Maria & 32 & - & 5 & 5 & - & 2 \\
\hline Outros locais & 22 & - & 8 & 9 & - & - \\
\hline Total & 444 & 13 & 205 & 189 & 1 & 11 \\
\hline
\end{tabular}




\section{ETNIA PARAKANÃ}

$\mathrm{Na}$ etnia Parakanã, foram conduzidos dois estudos em indígenas das aldeias Paranatinga e Maroxewara, da área indígena Parakanã que abrangia os Municípios de Itupiranga, Jacundá e Novo Repartimento; e em indígenas da aldeia Apyterewa, localizada fora dos limites da área Parakanã, nas margens do Igarapé Bom Jardim, afluente do Rio Xingu, Município de Altamira, todas as aldeias localizadas em municípios do Estado do Pará.

\section{EPIDEMIOLOGIA DOS VÍRUS DAS HEPATITES B, C E D NA TRIBO INDÍGENA PARAKANÃ, AMAZÔNIA ORIENTAL BRASILEIRA ${ }^{7}$}

Este estudo, financiado pelo IEC/FNS/MS e pelo Programa Parakanã/Centrais Elétricas do Norte do Brasil, teve como objetivo promover o levantamento, análise e discussão dos aspectos epidemiológicos relacionados à transmissão das hepatites $\mathrm{B}, \mathrm{C}$ e $\mathrm{D}$ na tribo indígena
Parakanã e estabelecer uma política adequada de prevenção e controle das infecções por esses vírus.

A escolha das aldeias Paranatinga e Maroxewara para o desenvolvimento do estudo ocorreu por: serem aldeias com uma população pequena e, em outubro de 1992, serem compostas por 350 indivíduos, com boa estrutura de serviços de saúde; pertencerem à mesma etnia, com situações diferenciadas, tanto em relação ao contato com outras comunidades quanto ao acesso mais difícil para a aldeia Maroxewara do que para a Paranatinga; estudos anteriores terem revelado prevalência considerável de infecção pelo $\mathrm{VHB}$; a necessidade de avaliar a eficácia da vacinação contra o VHB em áreas indígenas.

As aldeias estavam localizadas dentro dos limites da área Parakanã, a Paranatinga próxima ao igarapé Paranatinga e a Maroxewara às margens do Rio do Meio, ambos tributários de rios que desaguavam no rio Tocantins, represado pela Hidrelétrica de Tucuruí (Figura 1).

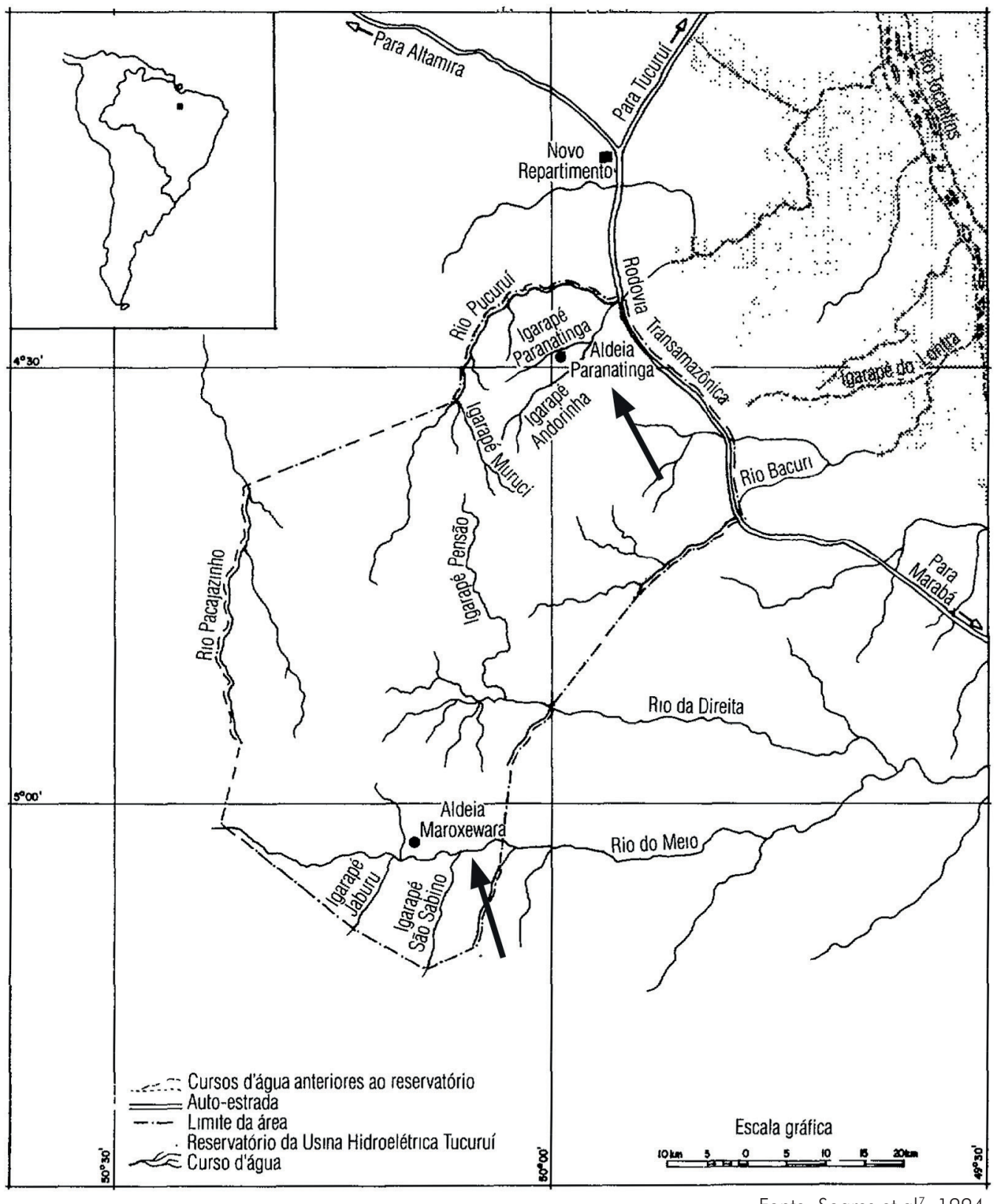

Figura 1 - Localização geográfica da área indígena Parakanã, Estado do Pará, Brasil 
Entre 9 e 16 de outubro de 1992, foram coletadas 339 amostras de soro de indígenas Parakanã, 210 da aldeia Paranatinga, 123 da Maroxewara; sendo que, na aldeia Paranatinga, também foram coletadas amostras de cinco esposas indígenas da etnia Suruí e, na aldeia Maroxewara, uma da etnia Assurini, totalizando 96,9\% amostras coletadas da população Parakanã. Também foram examinadas 106 amostras de soro coletadas entre os Parakanã na década de 1970.

Foram utilizados métodos imunoenzimáticos para marcadores das infecções pelos VHB, VHC e $\mathrm{VHD}$. Para $\circ \mathrm{VHB}$, foram testados $\circ \mathrm{HBsAg}$, anti-HBc (EIE-Organon) e anti-HBs (EIE-Abbott); para O VHC, foi testado o anti-VHC (EIE-Abbott-2 ${ }^{a}$ geracão), confirmado reagente por imunoblot (RIBA- $2^{a}$ geração), conforme critérios indicados pelo fabricante. Nas amostras $\mathrm{HBsAg}$ positivo, foram testados o anti-HBe, $\mathrm{HBeAg}$ e anti-HD (EIE-Organon).

$\mathrm{Na}$ aldeia Paranatinga, 0 estudo detectou prevalência total de $84,7 \%$ (182/215) de infecção pelo VHB, com 14,4\% (31/215) de portadores (Tabela 2), entre esses, a pesquisa de anti-HD foi negativa, sendo encontrada prevalência de infecção pelo $\mathrm{VHC}$ de $1,4 \%$ (3/215). Na aldeia Maroxewara, registrou-se 17,7\% (22/124) de prevalência total da infecção; não foram detectados portadores do VHB (Tabela 3) e houve prevalência de infecção pelo VHC de 1,6\% (2/124).

Em relação às 72 amostras de soro coletadas em 1974, na aldeia Paranatinga, e 34 coletadas em 1977, na aldeia Maroxewara, foram encontradas prevalências de $19,4 \%$ e 8,8\% de infectados pelo VHB, respectivamente. Todas essas amostras eram $\mathrm{HBsAg}$ e anti-VHC negativo.
O estudo destacou: a transmissão horizontal do VHB em idade precoce na aldeia Paranatinga; a diferença da prevalência entre os infectados de mesma etnia das duas aldeias geograficamente próximas; a baixa prevalência de infecção pelo VHB e a ausência de infecção pelo VHD nas duas aldeias.

Tabela 3 - Prevalência total de infectados pelo VHB na Aldeia Maroxewara*, por idade e sexo, outubro de 1992

\begin{tabular}{cccc}
\hline & Examinados/População & Infectados & $\%$ \\
\hline Grupo etário & & & \\
$<2$ anos & $10 / 14$ & - & - \\
$2-4$ anos & $23 / 23$ & - & - \\
$5-9$ anos & $23 / 23$ & 1 & 4,3 \\
$10-14$ anos & $12 / 12$ & - & - \\
$15-19$ anos & $15 / 15$ & 3 & 20,0 \\
$20-29$ anos & $18 / 18$ & 9 & 50,0 \\
$30-39$ anos & $15 / 15$ & 6 & 40,0 \\
$40-49$ anos & $4 / 4$ & 1 & 25,0 \\
$>49$ anos & $4 / 4$ & 2 & 50,0 \\
Sexo & & & \\
Masculino & $71 / 73$ & 14 & 19,7 \\
Feminino & $53 / 55$ & 8 & 15,1 \\
\hline Total & $124 / 128$ & 22 & 17,7 \\
\hline
\end{tabular}

* Inclui uma mulher Suruí; N: número de casos; \%: prevalência.

Sinal convencional utilizado: - Dado numérico igual a zero não resultante de arredondamento.

Tabela 2 - Prevalência de HBsAg e total de infectados pelo VHB na aldeia Paranatinga*, Estado do Pará, Brasil, por idade e sexo, outubro de 1992

\begin{tabular}{|c|c|c|c|c|c|}
\hline & \multirow{2}{*}{ Examinados/População } & \multicolumn{2}{|c|}{$\mathrm{HBsAg}$} & \multicolumn{2}{|c|}{ Total de infectados } \\
\hline & & $\mathrm{N}$ & $\%$ & N & $\%$ \\
\hline \multicolumn{6}{|l|}{ Grupo etário } \\
\hline $0-6$ meses & $6 / 7$ & - & - & 5 & 83,3 \\
\hline $6-11$ meses & $6 / 6$ & - & - & 3 & 50,0 \\
\hline $12-17$ meses & $7 / 7$ & - & - & 1 & 14,3 \\
\hline $18-23$ meses & $10 / 10$ & 2 & 20,0 & 5 & 50,0 \\
\hline $2-4$ anos & $31 / 31$ & 3 & 9,7 & 18 & 58,1 \\
\hline $5-9$ anos & $35 / 36$ & 10 & 28,6 & 34 & 97,1 \\
\hline $10-14$ anos & $28 / 29$ & 4 & 16,7 & 28 & 100,0 \\
\hline $15-19$ anos & $23 / 24$ & 1 & 4,3 & 20 & 86,9 \\
\hline $20-29$ anos & $25 / 26$ & 5 & 20,0 & 24 & 96,0 \\
\hline $30-39$ anos & 18/18 & 2 & 11,1 & 18 & 100,0 \\
\hline $40-49$ anos & $13 / 14$ & 1 & 7,7 & 13 & 100,0 \\
\hline$>49$ anos & $13 / 14$ & 3 & 23,1 & 13 & 100,0 \\
\hline \multicolumn{6}{|l|}{ Sexo } \\
\hline Masculino & $113 / 115$ & 22 & 19,5 & 102 & 90,3 \\
\hline Feminino & 102/107 & 9 & 8,8 & 80 & 78,4 \\
\hline Total & $215 / 222$ & 31 & 14,4 & 182 & 84,7 \\
\hline
\end{tabular}

* Inclui quatro mulheres Suruí e uma Assurini; N: número de casos; \%: prevalência.

Sinal convencional utilizado: - Dado numérico igual a zero não resultante de arredondamento. 
Por ocasião do inquérito sorológico, foi iniciada vacinação contra o VHB. Na aldeia Paranatinga, a vacinação prosseguiu entre os indígenas suscetíveis e, na aldeia Maroxewara, as doses subsequentes foram disponibilizadas para todos os indígenas. Foi implantado, a partir dessas ações, um programa de imunização voltado para todas as crianças nascidas após essa campanha.

estudo também forneceu informações sobre a presença de infecção pelo VHC nas duas aldeias. Dois indígenas, da aldeia Paranatinga, infectados pelo VHC, eram crianças de 6 e 12 anos de idade, uma delas com anti-VHC positivo em amostra de soro coletada três anos antes, resultado que foi confirmado seis meses depois. Houve ausência de infecção pelo VHD nas duas aldeias, entretanto a introdução desse agente na aldeia Paranatinga, que apresenta portadores do VHB, poderia acarretar graves consequências com relação à morbimortalidade por doença hepática crônica ou aguda, por superinfecção do VHD em indígenas portadores do VHB.

Dessa forma, concluiu-se ser oportuna a realização de estudo prospectivo, relacionado às infecções pelos VHB, VHC e VHD, entre os Parakanã, para avaliar a forma de transmissão desses agentes nas comunidades, onde o contato com os não índios possibilitavam a introdução desses vírus. Em relação ao VHB, medidas de intervenção são necessárias, principalmente quanto à vacinação nas aldeias Paranatinga e Maroxewara, devendo ser ampliada a todos os indígenas do Brasil, particularmente aos da Amazônia brasileira.

\section{ALDEIA APYTEREWA ${ }^{8}$}

Em 1995, foi conduzido estudo com o apoio da Companhia Vale do Rio Doce na aldeia Apyterewa, Município de Altamira, que era composta por 196 indígenas da etnia Parakanã, com a finalidade de realizar levantamento soroepidemiológico das infecções pelos vírus das hepatites; iniciar a vacinação contra - VHB; e assessorar um programa de vacinação na aldeia, atendendo as peculiaridades indígenas, conforme preconizado pelo Programa Nacional de Imunização (PNI).

Foi encontrada prevalência total da infecção pelo VHB acima de $90 \%$ e cerca de $6 \%$ de portadores do VHB (Gráfico 1).

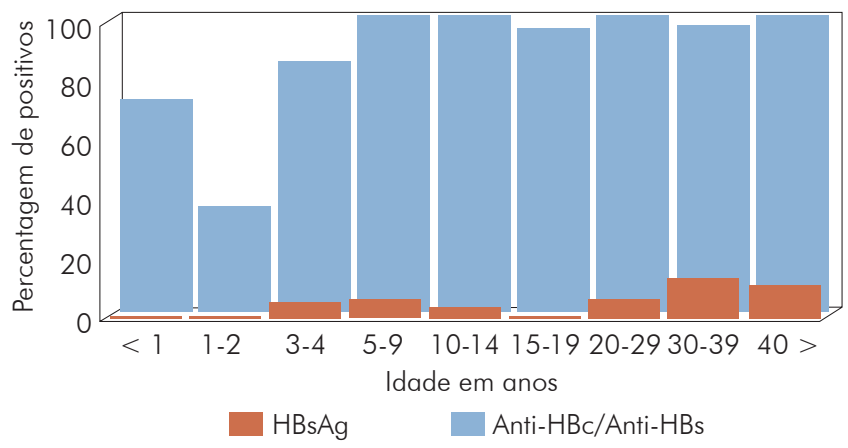

Gráfico 1 - Prevalência de marcadores sorológicos para a hepatite $B$ entre os indígenas da aldeia Apyterewa, Município de Altamira, Estado do Pará, Brasil, 1995

\section{EVOLUÇÃO SOROLÓGICA DE INDIVÍDUOS PORTADORES CRÔNICOS DO VHB NA TRIBO PARAKANÃ, AMAZÔNIA ORIENTAL BRASILEIRA ${ }^{8}$}

Devido à situação hiperendêmica para O VHB, encontrada em inquérito anterior (1992) na aldeia Paranatinga, com a colaboração do Subprograma de Saúde Parakanã e o Núcleo de Medicina Tropical da Universidade Federal do Pará, em 1997, nova coleta de amostras foi realizada entre os 28 portadores do VHB nessa aldeia, objetivando avaliar a evolução sorológica quanto aos marcadores de persistência, superinfecção pelo VHD e replicação viral. Foram pesquisados o $\mathrm{HBsAg}, \mathrm{HBeAg}$, anti-HBe e anti-HD, cujos resultados são apresentados na tabela 4 .

Tabela 4 - Frequência de marcadores sorológicos, nos anos de 1992 e 1997, de 28 portadores crônicos do VHB, Aldeia Paranatinga, tribo Parakanã, Estado do Pará, Brasil

\begin{tabular}{lrrrr}
\hline Marcadores & \multicolumn{2}{c}{1992} & \multicolumn{2}{c}{1997} \\
sorológicos & $N$ & $\%$ & \multicolumn{1}{c}{$\%$} & $\%$ \\
\hline HBsAg & 28 & 100,0 & 28 & 100,0 \\
HBeAg & 18 & 64,2 & 5 & 17,8 \\
Anti-HBe & 7 & 25,0 & 20 & 71,4 \\
Anti-HD & - & - & - & -
\end{tabular}

Fonte: Instituto Evandro Chagas, Relatório Trianual 1996/19986 Sinal convencional utilizado: - Dado numérico igual a zero não resultante de arredondamento.

Verificou-se que a prevalência do HBsAg manteve-se em 100\% entre os portadores crônicos. Houve negativação do marcador de replicação viral $\mathrm{HBeAg}$ e surgimento do anti-HBe em 13 indígenas, e nenhum caso de superinfecção pelo VHD foi observado.

\section{Capillaria hepatica (BANCROFT, 1893) (NEMATODA) ENTRE POPULAÇÕES INDÍGENAS E MAMÍFEROS SILVESTRES NO NOROESTE DO ESTADO DO MATO GROSSO, BRASIL, 2000'}

Capillaria hepatica, também conhecida como Calodium hepaticum ou Hepaticola hepatica, é um nematoide hepatotrópico da família Trichinellidae capaz de infectar roedores e outros mamíferos, inclusive, de forma esporádica, pode causar infecções em seres humanos.

Em decorrência da identificação de ovos semelhantes aos de C. hepatica em amostras de fezes de dois indígenas da aldeia Camararé, situada a noroeste do Estado do Mato Grosso, no período de 3 a 23 de outubro de 2000, atendendo à solicitação do Distrito Sanitário Especial Indígena (DSEI) Vilhena, uma equipe do IEC trabalhou junto às áreas indígenas Vale do Guaporé e Nambikwara, Estado do Mato Grosso, investigando a ocorrência desses ovos.

Foi realizado inquérito coproparasitológico, por método qualitativo direto, nas fezes de 477 (76,6\%) dos 622 indígenas das aldeias Mamaindé, Kithãulu, Camararé, Negaroté e Wassussu, dos vales dos rios Guaporé, e da aldeia Nambikwara situada a noroeste do Estado do Mato Grosso. 
Dos animais abatidos, como caça de subsistência, 10 fígados foram cedidos pelos indígenas, sendo fixados em formol a $10 \%$ para posterior avaliação histopatológica e parasitológica. Os cinco tipos de animais silvestres utilizados como fonte alimentar pelos indígenas foram: queixada (Tayassu pecari, Link, 1795); macaco-aranha (Ateles paniscus, Linnaeus, 1758); macaco-barrigudo (Lagothrix lagotricha, Humboldt, 1812); jabuti (Chelonoidis sp., Linnaeus, 1766) e um peixe de espécie não informada, para tentar correlacioná-los com a presença dos ovos de C. hepatica encontrados nas fezes desses indígenas.

Os resultados indicaram a presença de ovos de C. hepatica nas fezes de $8,6 \%$ (41/477) indígenas, assim como outros protozoários e helmintos enteroparasitas. Ovos de C. hepatica também foram identificados no fígado de T. pecari e A. paniscus.

A tabela 5 mostra a prevalência de C. hepatica encontrada nas aldeias das áreas indígenas Vale do Guaporé e Nambikwara; a maior prevalência, 19,6\% (12/61), ocorreu na aldeia Kithãulu; a média de idade foi de 30,2 anos (com variação de 2 meses a 64 anos), predominando a faixa etária de 5 a 14 anos.
Por meio do exame coproparasitológico, foram identificadas outras espécies de protozoários e helmintos. Entre os protozoários, a maior prevalência foi de Entamoeba coli (65\%) e Hymenolepis nana $(35,4 \%)$ e, entre os helmintos, Ascaris duodenalis (11,7\%) e Strongyloides stercoralis $(9,2 \%)$, sumarizados na tabela 6.

O exame macroscópico não identificou lesões nas vísceras dos animais. No exame histopatológico foi identificada a presença de ovos de C. hepatica em amostras de fígado das espécies T. pecari e A. paniscus. O tecido hepático apresentava preservação da arquitetura acinar, e os tratos portais exibiam discreta expansão fibrosa. Os ovos dos parasitas também foram encontrados no parênquima hepático, apresentando forma ovalar, cápsula estriada e opérculo bipolar não protuso, circundados por discreta reação inflamatória, constituída principalmente por infiltrado de linfócitos e eosinófilos, e não foram identificados vermes adultos.

A morfometria dos ovos de C. hepatica, obtidos por ocasião do exame parasitoscópico de fezes dos indígenas e das amostras de animais silvestres, mostrou similaridade, conforme apresenta a tabela 7 .

Tabela 5 - Ocorrência de casos de ovos de C. hepática nas fezes de indígenas de duas áreas do Estado do Mato Grosso, Brasil, outubro de 2000

\begin{tabular}{lcccccccccccccc}
\hline \multirow{2}{*}{ Aldeia } & $\begin{array}{c}\text { População } \\
\text { geral }\end{array}$ & $\begin{array}{c}\text { População } \\
\text { examinada }\end{array}$ & N & \% & \multicolumn{1}{c}{ Sexo } & \multicolumn{1}{c}{ Faixa etária (em anos) } \\
\hline Mamaindé & 159 & 134 & 15 & 11,2 & 9 & 6 & 1 & 2 & 7 & 2 & - & 2 & 1 \\
Kithãulu & 76 & 61 & 12 & 19,6 & 6 & 6 & - & 1 & 5 & 1 & 2 & - & - & 3 \\
Negaroté & 81 & 58 & 9 & 15,5 & 7 & 2 & - & 4 & 2 & 1 & 1 & - & 1 & - \\
Camararé & 95 & 78 & - & - & - & - & - & - & - & - & - & - & - & - \\
Nambikwara & 142 & 110 & - & - & - & - & - & - & - & - & - & - & - & - \\
Wassussu & 69 & 36 & 5 & 13,9 & 2 & 3 & - & - & - & 3 & 2 & - & - & - \\
\hline \multicolumn{1}{c}{ Total } & 622 & 477 & 41 & & 24 & 17 & 1 & 1 & 14 & 7 & 5 & 2 & 2 & 3 \\
\multicolumn{1}{c}{$\%$} & 100,0 & 76,7 & & 8,6 & 58,5 & 41,5 & 2,4 & 17,1 & 34,1 & 17,1 & 12,2 & 4,9 & 4,9 & 7,3 \\
\hline
\end{tabular}

M: masculino; F: feminino; N: número de casos; \%: prevalência.

Sinal convencional utilizado: - Dado numérico igual a zero não resultante de arredondamento.

Tabela 6 - Espécies de protozoários e helmintos identificados por exame coproparasitológico direto nas fezes de indígenas de duas áreas do Estado do Mato Grosso, Brasil, outubro de 2000

\begin{tabular}{|c|c|c|c|c|c|c|c|c|}
\hline \multirow{2}{*}{ Parasitas } & \multicolumn{6}{|c|}{ Aldeias } & \multirow{2}{*}{$\mathrm{N}$} & \multirow{2}{*}{$\%$} \\
\hline & Mamaindé & Kithãulu & Negaroté & Camararé & Nambikwara & Wassussu & & \\
\hline E. coli & 91 & 43 & 35 & 43 & 78 & 20 & 310 & 65,0 \\
\hline E. hystolitica & 15 & 26 & 15 & 25 & 43 & 13 & 137 & 28,7 \\
\hline E. nana & 2 & 6 & 5 & 12 & 28 & 2 & 55 & 11,5 \\
\hline G. lamblia & 6 & 2 & 2 & 5 & 13 & - & 28 & 5,8 \\
\hline H. nana & 51 & 21 & 22 & 31 & 39 & 5 & 169 & 35,4 \\
\hline I. butschilii & - & 2 & - & - & 4 & - & 6 & 1,2 \\
\hline A. duodenalis & 11 & 8 & 4 & 11 & 7 & 15 & 56 & 11,7 \\
\hline A. lumbricoides & 2 & - & - & 3 & - & 26 & 31 & 6,5 \\
\hline E. vermicularis & 1 & - & 3 & - & - & 3 & 7 & 1,4 \\
\hline S. stercoralis & 23 & 4 & 1 & 8 & 6 & 2 & 44 & 9,2 \\
\hline T. trichiurus & - & - & - & 1 & - & - & 1 & 0,2 \\
\hline C. hepatica & 15 & 12 & 9 & - & - & 5 & 41 & 8,6 \\
\hline
\end{tabular}

$\mathrm{N}$ : número de casos; \%: prevalência.

Sinal convencional utilizado: - Dado numérico igual a zero não resultante de arredondamento. 
Tabela 7 - Características morfométricas relativas a ovos de C. hepatica em fezes de humanos e fígados de animais da área indígena Nambikwara, Estado do Mato Grosso, Brasil, outubro de 2000

\begin{tabular}{|c|c|c|c|c|c|c|}
\hline \multirow{2}{*}{ Homens/Animais } & \multirow{2}{*}{$\begin{array}{l}\mathrm{N}^{\circ} \text { de ovos } \\
\text { mensurados }\end{array}$} & \multirow{2}{*}{ Amostra } & \multicolumn{2}{|c|}{ Tamanho dos ovos $(\mu \mathrm{m})$} & \multicolumn{2}{|c|}{ Média $(\mu \mathrm{m})$} \\
\hline & & & Comprimento & Largura & Comprimento & Largura \\
\hline Homem (índios Nambikwara) & 11 & Fezes & $61-68,6$ & $34-39,5$ & 64,8 & 37,9 \\
\hline Tayassu pecari (queixada) & 7 & Fígado & $60-66$ & $33-38$ & 63,2 & 35,6 \\
\hline Ateles paniscus (macaco-aranha) & 6 & Fígado & $56-61$ & $34-38$ & 58,4 & 35,5 \\
\hline
\end{tabular}

A prevalência de enteroparasitas entre os indígenas estava relacionada às precárias condições sanitárias existentes nas aldeias; ao contato direto, tanto com animais domésticos como com animais silvestres considerados "domesticados"; à contaminação das fontes de abastecimento de água pelo destino inadequado dos dejetos; e pelo consumo de água sem qualquer tratamento.

A presença de C. hepatica nas fezes desses indígenas foi considerada infecção pseudoparasitária devido à ingestão de vísceras de animais silvestres infectados, confirmada pela presença de ovos do parasita no fígado de T. pecari e A. paniscus, duas espécies consideradas hospedeiros naturais da C. hepatica.

A eliminação fecal de ovos de C. hepatica entre os indígenas representa infecções não genuínas, estando associadas ao consumo de vísceras de animais silvestres. Concluiu-se que estudos clínico-epidemiológicos serão necessários junto a essas populações, devido ao potencial zoonótico do parasita em causar infecções genuínas de capilaríase hepática.

\section{INFECÇÃO PELO VÍRUS DA HEPATITE A EM ÁREA INDÍGENA DA AMAZÔNIA BRASILEIRA ${ }^{10}$}

A hepatite $A$, importante problema de saúde pública mundial, está relacionada a deficientes condições socioeconômicas e de higiene da população, tendo como agente etiológico o vírus da hepatite $A(\mathrm{VHA})$, da família Picornaviridae, gênero Hepatovirus, espécie Hepatovirus $A$.

Esse estudo objetivou avaliar a prevalência da infecção pelo VHA em aldeia de etnia Xikrin, Município de Altamira, cuja investigação solicitada pelo DSEI Altamira foi desencadeada pelo óbito de uma criança indígena, com 6 anos de idade que apresentou quadro séptico e hepatite, contudo sem a devida confirmação laboratorial.

Em novembro de 2002, foram coletadas amostras de sangue de indígenas da etnia Xikrin, residentes na aldeia Bakajá, as quais foram analisadas por meio de testes sorológicos dos marcadores virais das hepatites $A$ (anti-VHA lgM, anti-VHA total), B (HBsAg, anti-HBc total, anti-HBs), C (anti-VHC) e D (anti-HD total nas amostras $\mathrm{HBs} A g+)$, por técnica imunoenzimática.

$\bigcirc$ estudo incluiu 325 indígenas, com maior frequência do sexo masculino $(51,4 \%)$, média de idade de 37,5 anos (variação entre 1 e 74 anos de idade).
Foi encontrada prevalência de $98 \%$ para o anti-VHA total e de $30,5 \%$ para o anti-VHA IgM, entre esses, $89 \%$ estavam na faixa etária de até 10 anos, não havendo predominância quanto ao sexo (Tabela 8). Houve positividade de 0,9\% (3/352) para o $\mathrm{HBsAg}$, de $19 \%$ (16/352) anti-HBc total e nenhuma amostra foi reagente para o anti-VHC e anti-HD.

Tabela 8 - Prevalência de anticorpos contra o VHA em indígenas de aldeia Xikrin, por faixa etária e sexo, Altamira, Estado do Pará, Brasil, novembro de 2002

\begin{tabular}{|c|c|c|c|c|c|}
\hline \multirow{2}{*}{ Variáveis } & \multirow{2}{*}{$\begin{array}{l}\text { População } \\
\text { examinada }\end{array}$} & \multicolumn{2}{|c|}{ Anti-VHA total+ } & \multicolumn{2}{|c|}{ Anti-VHA lgM+ } \\
\hline & & N & $\%$ & N & $\%$ \\
\hline \multicolumn{6}{|c|}{ Faixa etária (anos) } \\
\hline $1-4$ & 79 & 76 & 96,2 & 50 & 65,8 \\
\hline $5-9$ & 76 & 76 & 100,0 & 43 & 56,6 \\
\hline 10-14 & 50 & 49 & 98,0 & 5 & 10,2 \\
\hline $15-19$ & 31 & 30 & 97,8 & 3 & 10,0 \\
\hline $20-24$ & 27 & 27 & 100,0 & 1 & 3,7 \\
\hline $25-29$ & 24 & 24 & 100,0 & - & - \\
\hline 30-34 & 16 & 15 & 94,0 & 1 & 6,7 \\
\hline 35-39 & 8 & 8 & 100,0 & 1 & 12,5 \\
\hline $40-44$ & 9 & 9 & 100,0 & - & - \\
\hline $45-49$ & 10 & 10 & 100,0 & - & - \\
\hline $50-54$ & 4 & 4 & 100,0 & - & - \\
\hline 55-59 & 6 & 6 & 100,0 & 1 & 16,7 \\
\hline $60-64$ & 7 & 7 & 100,0 & - & - \\
\hline $65-69$ & 3 & 3 & 100,0 & - & - \\
\hline 70-74 & 2 & 2 & 100,0 & - & - \\
\hline \multicolumn{6}{|l|}{ Sexo } \\
\hline Masculino & 181 & 178 & 98,3 & 52 & 29,2 \\
\hline Feminino & 171 & 167 & 97,7 & 53 & 31,8 \\
\hline Total & 352 & 345 & 98,0 & 105 & 30,5 \\
\hline
\end{tabular}

$\mathrm{N}$ : número de casos; \%: prevalência.

Sinal convencional utilizado: - Dado numérico igual a zero não resultante de arredondamento.

Foi caracterizado, em base laboratorial, um surto de infecção pelo VHA na aldeia Bakajá, de etnia Xikrin, possivelmente associado à ocorrência do óbito da criança indígena que desencadeou a investigação. 


\section{PREVALÊNCIA DOS MARCADORES SOROLÓGICOS DOS VHB E VHD NA ÁREA INDÍGENA APYTEREWA, DO GRUPO PARAKANÃ, PARÁ, BRASIL ${ }^{11,12}$}

Os objetivos desse estudo foram 0 de determinar a prevalência dos marcadores sorológicos dos $\mathrm{VHB}$ e $\mathrm{VHD}$, nas aldeias indígenas Apyterewa e Xingu, da etnia Parakanã; comparar a frequência desses marcadores com os resultados encontrados em 1995; analisar a resposta vacinal contra a hepatite $\mathrm{B}$; e avaliar, nos portadores do VHB, o estado de replicação viral.

Contatos foram feitos entre a chefia do DSEI Altamira e a SAHEP/IEC sobre a continuidade do inquérito soroepidemiológico iniciado na aldeia Apyterewa, em 1995. Técnicos da SAHEP/IEC foram deslocados para as aldeias, em setembro de 2004, e coletaram $258 \quad(77,5 \%$ do total de indígenas das aldeias) amostras, sendo 167 da aldeia Apyterewa e 91 da aldeia Xingu. A idade variou entre 1 mês e 77 anos, com média e mediana de 19 e 15 anos, respectivamente.

Os exames foram realizados na SAHEP/IEC por técnica imunoenzimática (ELISA), utilizando kits comerciais. As amostras foram testadas para a presença do VHB ( $\mathrm{HBsAg}$, anti-HBc total e anti-HBs) e, nas amostras $\mathrm{HBsAg}$ reagente, foram pesquisados $\circ \mathrm{HBeAg}$, anti-HBe e anti-HD total.
Nas 258 amostras, foi encontrada prevalência total de infecção pelo VHB de 55,7\% na aldeia Apyterewa e $49,5 \%$ na Xingu. Detectou-se 3,9\% (10/258) de prevalência para $\circ \mathrm{HBsAg}+; 53,5 \%(138 / 258)$ para $\circ$ anti-HBc total+/anti-HBs+ e 31,4\% (81/258) para o anti-HBs + isolado. Entre as amostras $\mathrm{HBsAg}$ reagente, houve prevalência de $20 \%$ para $\circ \mathrm{HBeAg}+, 60 \%$ para o anti-HBe+ e o anti-HD total mostrou-se negativo.

$\mathrm{Na}$ tabela 9, foram comparados os resultados dos marcadores sorológicos das hepatites $B$ e $D$ encontrados no inquérito soroepidemiológico de 1995, levantados junto ao banco de dados da SAHEP, e os resultados encontrados no estudo de 2004.

Em 1995, a prevalência do $\mathrm{HBsAg}+$ era de 5,6\% (1 1/196); não foram detectados portadores do VHB em crianças abaixo de 3 anos idade; e a maior prevalência de portadores do VHB, 14,3\% (4/28), ocorria na faixa etária dos 30 aos 39 anos. A prevalência detectada de anti-HBc total+/anti-HBs+ era de 69,9\% (137/196), com a mais baixa prevalência entre 7 e 11 meses de idade, e a maior, 96,4\% (27/28), entre 10 e 14 anos de idade; $66,7 \%(4 / 6)$ desses anticorpos encontravam-se em menores de 6 meses de idade, e a infecção pelo VHB ocorria de forma precoce, desde o primeiro ano de vida, alcançando $52,9 \%(18 / 34)$ das crianças entre 1 e 4 anos de idade. Não foi detectado anti-HBs + sob a forma isolada (Gráfico 2).

Tabela 9 - Distribuição da prevalência dos marcadores sorológicos dos VHB e VHD das aldeias Apyłerewa e Xingu, por ano de estudo, Altamira, Estado do Pará, Brasil, 1995 e 2004

\begin{tabular}{|c|c|c|c|c|c|c|c|c|c|c|c|c|}
\hline \multirow{2}{*}{ Ano } & \multirow{2}{*}{ Aldeias } & \multirow{2}{*}{$\begin{array}{l}\text { População } \\
\text { examinada }\end{array}$} & \multicolumn{2}{|c|}{$\mathrm{HBsAg}+$} & \multicolumn{2}{|c|}{$\begin{array}{c}\text { Anti-HBc total+/ } \\
\text { Anti-HBs }+\end{array}$} & \multicolumn{2}{|c|}{$\begin{array}{c}\text { Anti-HBs+ } \\
\text { isolado }\end{array}$} & \multicolumn{2}{|c|}{$\mathrm{HBeAg}+$} & \multicolumn{2}{|c|}{ Anti-HBe+ } \\
\hline & & & $\mathrm{N}$ & $\%$ & $\mathrm{~N}$ & $\%$ & $\mathrm{~N}$ & $\%$ & $N$ & $\%$ & $\mathrm{~N}$ & $\%$ \\
\hline \multirow{2}{*}{$1995^{*}$} & Apyłerewa & 117 & 9 & 7,7 & 75 & 64,1 & - & - & 5 & 55,6 & 4 & 44,4 \\
\hline & Total & 196 & 11 & 5,6 & 137 & 69,9 & - & - & 7 & 63,6 & 4 & 36,4 \\
\hline \multirow{3}{*}{2004} & Apyterewa & 167 & 9 & 5,4 & 93 & 55,7 & 45 & 26,9 & 2 & 22,2 & 6 & 66,7 \\
\hline & Xingu & 91 & 1 & 1,1 & 45 & 49,5 & 36 & 39,6 & - & - & - & - \\
\hline & Total & 258 & 10 & 3,9 & 138 & 53,5 & 81 & 31,4 & 2 & 20,0 & 6 & 60,0 \\
\hline
\end{tabular}

* As informações de 1995 foram coletadas utilizando o banco de dados da SAHEP/IEC; N: número de casos; \%: prevalência.

Sinal convencional utilizado: - Dado numérico igual a zero não resultante de arredondamento.

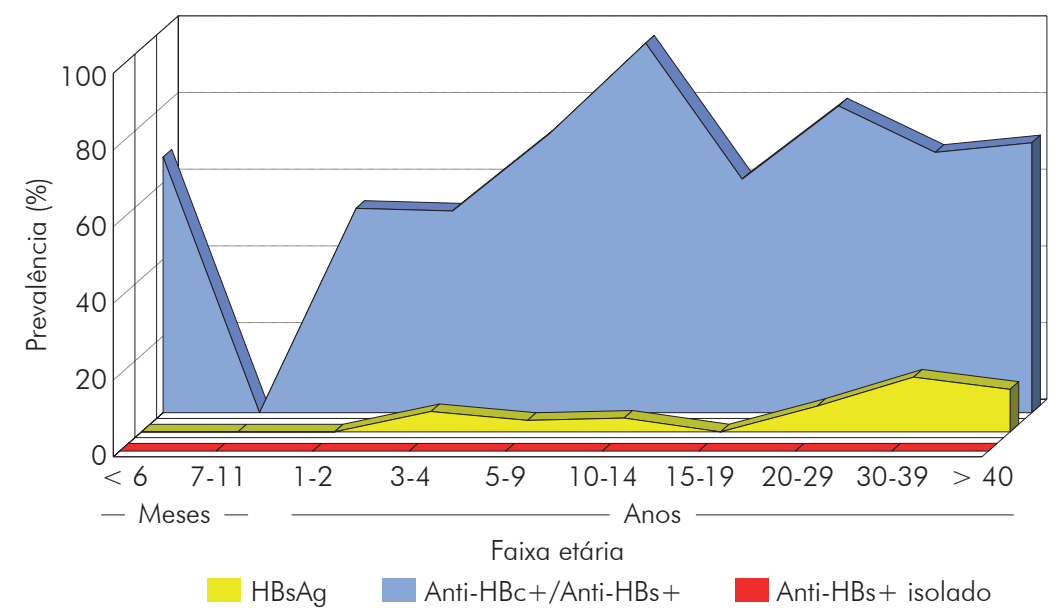

Gráfico 2 -Prevalência de $\mathrm{HBsAg}+$, anti-HBc total+/anti-HBs+ e anti-HBs+ isolado por faixa etária, nas aldeias Apyterewa e Xingu, Município de Altamira, Estado do Pará, Brasil, 1995 
No ano de 2004, a prevalência de HBsAg + foi de $3,9 \%(10 / 258)$ e somente foram detectados portadores do VHB acima de 10 anos de idade. A maior prevalência de portadores do vírus, 14\% (6/43), estava acima da faixa de 40 anos de idade. A prevalência de anti-HBc total+/anti-HBs+ foi de 53,5\% (138/258); presenciou-se esses anticorpos em $60 \%(6 / 10)$ dos menores de 6 meses de idade; e ocorreu infecção pelo VHB desde o primeiro ano de vida em $4 \%(1 / 25)$ das crianças entre 1 e 2 anos de idade. Foi encontrada prevalência de anti-HBs + isolado em 31,4\% (81/258) das amostras examinadas (Gráfico 3).

O estudo identificou, na aldeia Apyterewa, $5,4 \%$ de portadores do vírus ( $\mathrm{HBsAg}$ ) e a presença de infecção anterior pelo $\mathrm{VHB}$ de 55,7\% (anti$\mathrm{HBc}$ total+/anti-HBs+); e, na aldeia Xingu, 1,1\% de portadores do vírus, com 49,5\% de infectados anteriormente pelo VHB.

A frequência de portadores do VHB foi cinco vezes maior na aldeia Apyterewa do que na Xingu, classificou-se a primeira como de moderada endemicidade e a segunda como de baixa endemicidade, revelando a heterogeneidade de prevalência entre as aldeias, mesmo estando geograficamente próximas e sendo da mesma etnia.

A prevalência de portadores do VHB entre os indivíduos maiores de 10 anos de idade, na aldeia Apyterewa, e de 20 anos de idade, na Xingu, evidenciou que a transmissão horizontal era mais importante que a transmissão vertical. A transmissão sexual pode ser expressiva nessas populações pela presença de indivíduos em idade sexualmente ativa, portanto potencialmente transmissores da infecção pelo VHB.

Comparando os inquéritos de 1995 e 2004 nessas aldeias, percebeu-se que, nos últimos nove anos, ocorreram a redução da prevalência de portadores do $\mathrm{VHB}$, a redução da prevalência dos marcadores anti-HBc total+/anti-HBs+ e que a resposta vacinal, ausente em 1995, pois a vacinação contra ○ VHB foi introduzida nas aldeias somente a partir daquele ano, mostrou-se evidente em 2004, com o surgimento de perfil vacinal entre os suscetíveis.

Quanto à faixa etária, a comparação dos dois inquéritos evidenciou que, em 1995, havia portadores do VHB desde os 3 anos de idade, com maior frequência na faixa etária de 30 a 39 anos. Em 2004, os portadores do vírus estavam acima de 10 anos de idade e a maior frequência encontrava-se entre indivíduos acima de 40 anos, com deslocamento da faixa etária desses portadores para faixas mais elevadas, havendo a possibilidade de, em longo prazo, ocorrer diminuição do número de portadores do VHB se medidas de prevenção fossem mantidas nas comunidades.

Ocorreu redução da frequência de anti-HBc total+/anti-HBs + nos menores de 6 meses de idade; surgimento de indivíduos suscetíveis e presença de infecção pelo VHB precocemente desde o primeiro ano de vida, apesar de a prevalência desses marcadores, entre menores de 2 anos de idade, em 2004, ter sido nitidamente menor que a de 1995.

O estudo de 2004 detectou o surgimento de perfil vacinal entre os suscetíveis, tanto na aldeia Apyterewa como na Xingu, revelando, entretanto, baixa prevalência de anti-HBs+ isolado em menores de 1 ano de idade, mostrando ser necessário reavaliar a vacinação contra - VHB nas aldeias, com o objetivo de melhorar a cobertura vacinal, principalmente entre as crianças menores de 1 ano de idade.

Em ambos os inquéritos, não foram detectados indivíduos com sorologia positiva para $\circ$ VHD, admitindo-se a não introdução do vírus nessas aldeias, entretanto a presença de indivíduos com infecção pregressa e de portadores do VHB indica ser possível a introdução desses vírus nas comunidades, caso medidas de prevenção e controle não fossem aplicadas.

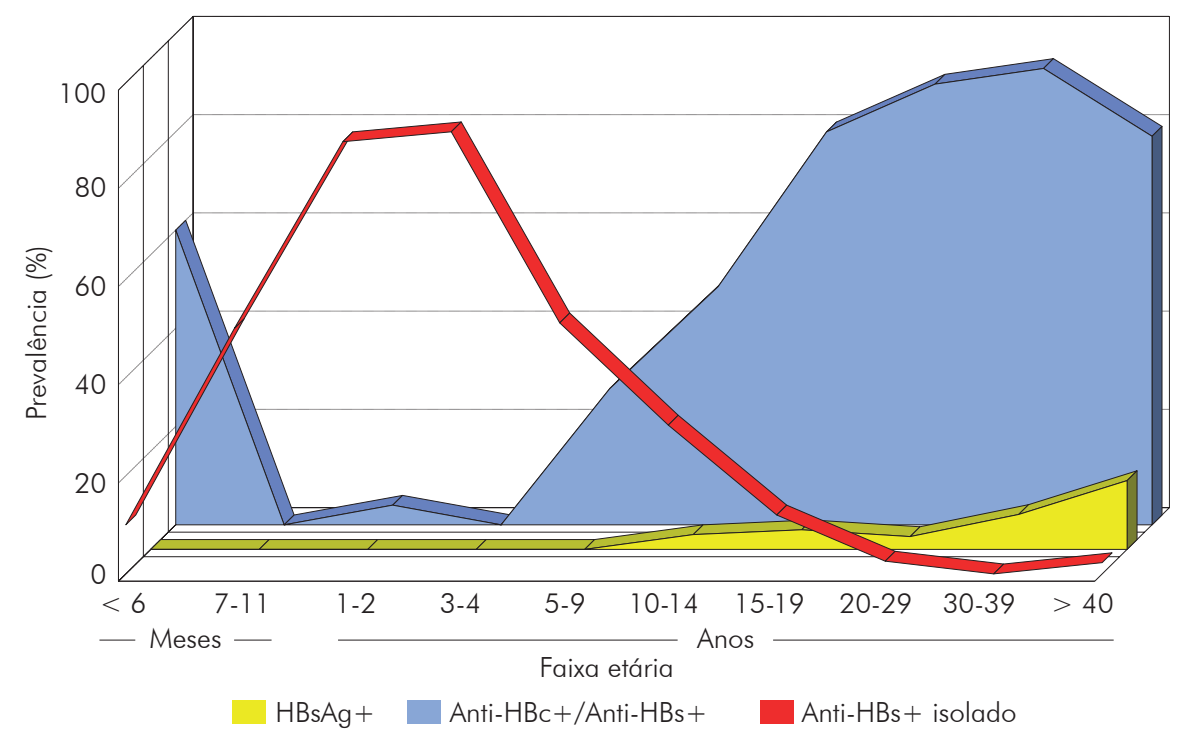

Gráfico 3 -Prevalência de $\mathrm{HBsAg}+$, anti-HBc total+/anti-HBs+ e anti-HBs+ isolado por faixa etária, nas aldeias Apyterewa e Xingu, Município de Altamira, Estado do Pará, Brasil, 2004 
estudo não possibilitou a determinação de quando ocorreu a introdução do VHB nas aldeias, uma vez que aspectos culturais, como, por exemplo, a perfuração do lábio inferior nos homens e nas orelhas das mulheres; a infestação de piolhos, comuns nas aldeias; o início precoce de práticas sexuais, muitas vezes com múltiplos parceiros; a grande quantidade de insetos hematófagos presentes nas aldeias, proporcionando a transmissão mecânica; lesões como impetigo, escabiose e piodermites, atuando como portas de entrada para a infecção pelo VHB; arranhões produzidos por galhos e espinhos nas matas onde habitam; o contato familiar com portadores do VHB; o compartilhamento de objetos e utensílios, tanto na alimentação como na higiene corporal; tatuagens e escarificações rituais podem atuar no favorecimento da transmissão do vírus entre os indígenas.

Em base laboratorial, foi caracterizada, entre as populações estudadas, a ocorrência de portadores crônicos do VHB e a emergência de perfil vacinal contra - VHB entre os suscetíveis, ratificando a efetividade e a necessidade de manter a vacinação contra o VHB, principalmente no primeiro ano de vida, para evitar a transmissão vertical. A ausência de portadores do VHD mostrou a necessidade de desenvolver vigilância epidemiológica efetiva para detecção precoce da infecção pelo VHD entre os portadores do VHB.

\section{CONSIDERAÇÕES FINAIS}

De acordo com o censo de 2010 do Instituto Brasileiro de Geografia e Estátistica ${ }^{13}$, a maior parte dos índios brasileiros vive na Amazônia. Os serviços de atenção à saúde indígena são coordenados pela Secretaria Especial de Saúde Indígena do MS, a qual foi criada em outubro de 2010 para desenvolver a Política Nacional de Atenção à Saúde dos Povos Indígenas e o processo de gestão do Subsistema de Atenção à Saúde Indígena, no âmbito do Sistema Único de Saúde (SASI-SUS). Essa Secretaria surgiu pela necessidade de reformular a gestão da saúde indígena no País, demandada pelos indígenas durante as Conferências Nacionais de Saúde Indígena, e tem como missão implementar um modelo de gestão e de atenção no âmbito do SASI-SUS, descentralizado, com autonomia administrativa, orçamentária, financeira e responsabilidade sanitária dos 34 Distritos Sanitários Especiais Indígenas ${ }^{14}$.

O IEC, pela ênfase da sua atuação junto ao território e à população da Amazônia, no decorrer de sua histórica trajetória, tem trabalhado com informações acerca desse tema, marcadamente no que se refere à vigilância das endemias, epidemias e das ações de saúde coletiva afins. Como tratado no presente manuscrito, os primeiros estudos mais sistemáticos com populações indígenas e hepatopatias datam do final da década de 1980, envolvendo diversas etnias da Amazônia brasileira. Resguardar os princípios que regem a bioética afinada à questão é um dos cuidados na abordagem da temática. Contudo, acredita-se que nenhum estudo, considerando a construção de um território saudável amazônico, possa ser realizado sem o curso da devida atenção concomitante ao processo de saúde indígena. Dessa forma, minimamente, deve ser a obrigação de todas as instituições oficiais ligadas, direta ou indiretamente, à saúde desses povos, formar profissionais, atuar, informar e refletir sobre as questões ligadas às comunidades indígenas no Brasil, de modo geral e, em particular, para a Amazônia ${ }^{15}$.

\section{REFERÊNCIAS}

1 Bensabath G, Soares MCP. A evolução do conhecimento sobre as hepatites virais na região amazônica: da epidemiologia e etiologia à prevenção. Rev Soc Bras Med Trop. 2004;37 supl 2:14-26.

2 Rodrigues Filho A, Salles JM, Viana CM, Leitão EL. Febre negra: considerações sobre aspectos clínicos. Rev UFPA. $1971 ; 1$ (2):321-40.

3 Bensabath G, Soares MCP, Maia MMS. Hepatites por vírus. In: Ministério da Saúde (BR). Fundação Serviços de Saúde Pública. Instituto Evandro Chagas: 50 anos de contribuição às ciências biológicas e à medicina tropical. Belém: Fundação Serviços de Saúde Pública; 1986. p. 483-529.

4 Soares MCP, Bensabath G. Tribos indígenas da Amazônia Oriental como população de risco para a hepatite D (Delta) [carta]. Rev Inst Med Trop Sao Paulo. 1991 mai-jun;33(3):241-2.
5 Hadler SC, Monzo M, Ponzetto A, Anzola E, Rivero $D$, Mondolfi $A$, et al. Delta virus infection and severe hepatitis: an epidemic in the Yucpa Indians of Venezuela. Ann Intern Med. 1984 Mar; 100(3):339-44.

6 Ministério da Saúde (BR). Fundação Nacional de Saúde. Instituto Evandro Chagas. Relatório qüinqüenal 1991/1995. Belém: Instituto Evandro Chagas; 1996.

7 Soares MCP, Menezes RC, Martins SJ, Bensabath G. Epidemiologia dos vírus das hepatites $B, C$ e D na tribo indígena Parakanã, Amazônia Oriental Brasileira. Bol Oficina Sanit Panam. 1994 ago;1 17(2):124-34.

8 Ministério da Saúde (BR). Secretaria de Vigilância em Saúde. Instituto Evandro Chagas. Relatório trianual 1996/1998. Belém: Instituto Evandro Chagas; 2003.

9 Soares MCP, Nunes HM, Silveira FAA, Alves MM, Souza AJS. Capillaria hepatica (Bancroft, 1893) (Nematoda) entre populações indígenas e mamíferos silvestres no noroeste do Estado do Mato Grosso, Brasil, 2000. Rev Pan-Amaz Saude. 2011 set;2(3):35-40. 
10 Nunes HM, Soares MCP, Silva HMR. Infecção pelo vírus da hepatite $A$ em área indígena da Amazônia oriental brasileira. Rev Soc Bras Med Trop. 2004;37 supl 2:52-6.

11 Nunes HM, Monteiro MRCC, Soares MCP. Prevalência dos marcadores sorológicos dos vírus das hepatites $B$ e $D$ na área indígena Apyterewa, do grupo Parakanã, Pará, Brasil. Cad Saude Publica. 2007 nov;23(1 1):2756-66.

12 Nunes HM. Prevalência dos marcadores sorológicos dos vírus das hepatites $\mathrm{B}$ e $\mathrm{D}$ na área indígena Apyterewa, do grupo Parakanã, Pará, Brasil [dissertação]. Belém (PA): Universidade Federal do Pará, Núcleo de Medicina Tropical; 2005.
13 Instituto Brasileiro de Geografia e Estatística. Os indígenas no censo demográfico 2010: características gerais dos indígenas: resultados do universo [Internet]. Rio de Janeiro: IBGE; 2010 [citado 2016 mai 13]. Disponível em: http://indigenas.ibge.gov.br/images/ indigenas/estudos/indigena_censo2010.pdf.

14 Ministério da Saúde (BR). Secretaria de Vigilância em Saúde. Secretaria Especial de Saúde Indígena. Conheça a Secretaria - Sesai [Internet]. Brasília: Ministério da Saúde; 2016 [citado 2016 abr 26]. Disponível em http://portalsaude.saude.gov.br/ index.php/conheca-a-secretaria-sesai.

15 Soares MCP. Saúde indígena: algumas informações e reflexões durante o caminhar. Rev Paraense Med. 2000 mai-ago; 1 4(2):49-52. 